\title{
Standardisation of ceramic matrix composites
}

\author{
Philippe Gomez ${ }^{\mathrm{a}}$ \\ DGA Aeronautical Systems, 47 rue Saint Jean, 31131 Balma Cedex, France
}

\begin{abstract}
The standardisation on ceramic matrix composite (CMCs) test methods occurred in the 1980's as these materials began to display interesting properties for aeronautical applications. Since the French Office of standardisation B43C has participated in establishing more than 40 standards and guides dealing with their thermal mechanical properties, their reinforcement and their fibre/matrix interface. As their maturity has been demonstrated through several technological development programmes (plugs, flaps, blades ...), the air framers and engine manufacturers are now thinking of develop industrial parts which require a certification from airworthiness authorities. Now the standardisation of CMCs has to turn toward documents completing the certification requirement for civil and military applications. The news standards will allow being more confident with CMCs in taking into account their specificity.
\end{abstract}

\section{Introduction}

The development of ceramic matrix composites (CMCs) began several decades ago when the requirement for lighter materials that could sustain high temperatures became necessary.

Quickly, people involved with CMCs started to discuss and to establish standards in order to achieve common basic material properties.

More recently CMCs demonstrated their maturity through the success of technological development programmes (plugs, flaps, blades ...). Consequently air framers and engine makers included CMCs for possible usage in their programmes.

Currently in civil aeronautics, the CMC applications are at the certification stage and industry has to obtain the airworthiness certificate.

Now the standardisation of CMCs has to turn towards documentation to complete the certification requirement for civil and military applications. The new standards will help industry and authorities by establishing a common basis for discussion and allow then to be more confident with CMCs when taking into account their unique characteristics.

\section{Brief history of CMCs in France}

The CMCs arrived on the market in the early of the 70's to respond to spatial propulsion requirements. We are including carbon/carbon composites (C/C) in the family of CMCs.

\footnotetext{
a e-mail: philippe.gomez@intradef .gouv.fr
}

This is an Open Access article distributed under the terms of the Creative Commons Attribution License 4.0, which permits unrestricted use, distribution, and reproduction in any medium, provided the original work is properly cited. 


\section{MATEC Web of Conferences}

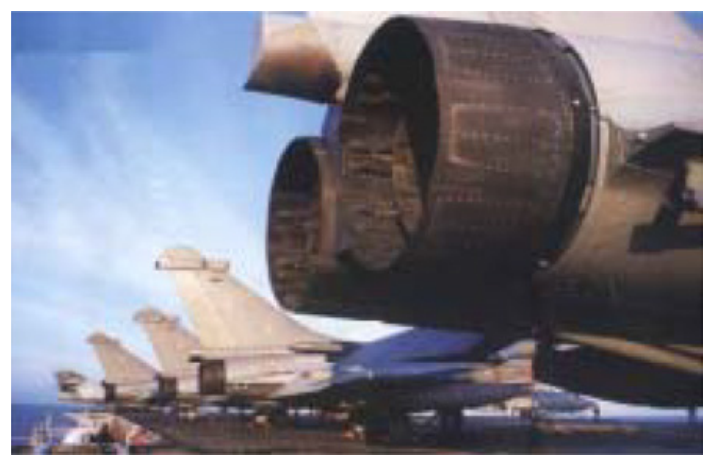

Figure 1. $\mathrm{C} / \mathrm{SiC}$ secondary flaps of the M88, engine of the French fighting aircraft Rafale.

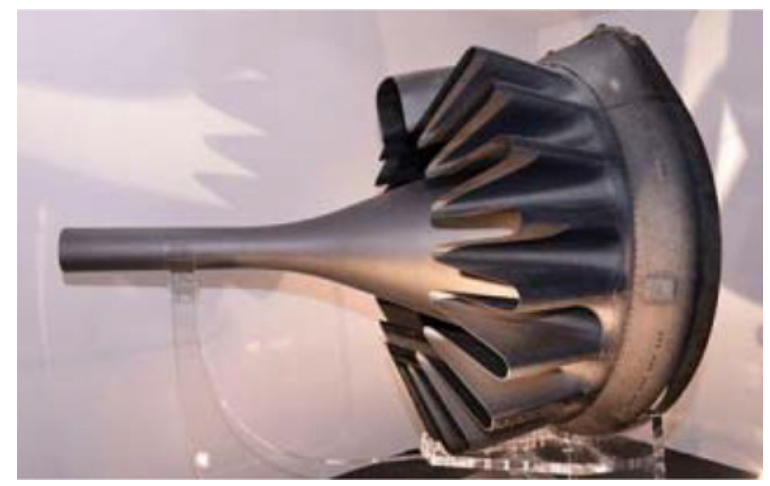

Figure 2. CFM56 CMC plug demonstrator. Developed by Herakles and tested in flight on an Airbus A320.

Since this period, $\mathrm{C} / \mathrm{C}$ composites have been used for rocket throat nozzle as well as divergent and expendable divergent. Nevertheless, the probable most important use of $\mathrm{C} / \mathrm{C}$ in volume is discs for aircraft brakes.

In the 80's Europe launched a programme of development of a re utilizable space shuttle named Hermes. The necessity to operate a long time at high temperature under oxidant atmosphere excluded $\mathrm{C} / \mathrm{C}$ as potential candidate. This opened the way to develop $\mathrm{C} / \mathrm{SiC}$ and $\mathrm{SiC} / \mathrm{SiC}$.

When the European space shuttle programme collapsed in 1992, the companies working on CMCs took advantage of their experience to set up a second generation of CMCs which could be adapted to aeronautical challenges. The temperature of material requirements decreased but the operating duration exploded: tens of hours for a space shuttle, thousands of hours for military engine aircraft and then tens of thousands of hours for civil engine aircraft.

The first aeronautical CMCs applications were produced in the frame of military programmes. They aimed to demonstrate the feasibility of different engine parts such as flaps, combustion chambers, nozzles, plugs ... In 1996, the C/SiC secondary flaps of the M88, engine of the French fighting aircraft Rafale, were the first parts qualified for flight.

The third generation of CMCs appeared in the early 2000's with thermo mechanical characteristics and life durations which suggested this kind of material was mature enough for more critical applications and/or for civil applications. The CMCs seemed to be a good candidate to meet the lightening and performance requirements for engine hot parts and to replace nickel based superalloys whenever possible. 


\section{Data material requirements for design}

Engine makers continuously search materials capable of sustaining ever higher temperature in order to increase the thermodynamic efficiency of their turbo machines. Initially they were interested by monolithic ceramics which displayed lower density and higher thermal resistance than alloys usually employed in the hot parts. Unfortunately, the brittle behaviour of the monolithic ceramic made their use impossible in the aeronautical field.

The CMCs provided a solution that avoided brittle behaviour by introducing a ceramic fibre into a ceramic matrix. This structure allowed a crack deflection inside the fibre coating and increases the crack propagation energy. Then the CMCs showed an elastic damageable behaviour due to the matrix microcracks. The maximum elongation at failure increased at about $1 \%$.

At the same time the design offices size parts with well-established methods to predict their behaviour and their life. These methods are suitable for homogeneous and isotropic materials but are not adapted for CMCs which are nonhomogeneous and exhibit an orthotropic behaviour.

Models and methods to size CMC components developed require material data. New specific tests different from the existing tests used for monolithic ceramics, metallic alloys and organic matrix composites had to be developed.

\section{Standardization and its evolution}

During the 80's in France, industries (Aérospatiale, SEP, Dassault, ...) and test centres (CEAT, IMC, ... ) worked on test methods to achieve thermo mechanical properties from CMC coupons. At the same time, academics (LCTS, LMT, INSA Lyon, ... ) and institutional laboratories (ONERA, ...) developed constitutive equations and fatigue life models.

In 1987, most of them created the technical committee of the AFNOR B43C standard commission which dealt with technical ceramic topics. The purpose was to harmonize test methods for CMCs thermal and mechanical characterisation.

In 1988, the members of the AFNOR approached the European Standard Commission CEN TC184 and the subcommittee SC1 dealing with CMCs was born. During a period of 15 years the subcommittee SC1 discussed, wrote and published approximatively 40 standards and guides (see the table below).

Finally the French standard commission joined in 2008 the ISO TC206 Technical Committee as participant member of the Working Group 4 dealing with ceramic matrix composites. This was to transfer the European corpus of standards about CMC to the ISO level. Additionally new standards could be developed to cover other requirements, such as in support of the airworthiness certification process.

The standards established cover topics of elementary mechanical (tensile, compression, ...) and thermal (expansion, diffusivity, ...) properties of the composite at room temperature and at high temperature. Furthermore we can find standards about life of the material under creep or fatigue conditions under inert or oxidative atmospheres.

There are also standards to determine reinforcement properties and characteristics. To complete there are standards to evaluate fibre/matrix properties interface properties, terms and symbols definition. The Table 1 below shows the number of standards by domain. The Table 2 gives the references of the French standards for mechanical tests and their ISO, American and Japanese, equivalents.

\section{Emerging applications and new requirements: The example of aeronautic}

Since the 2000's, CMCs have shown properties in terms of strength and life over a wide temperature range which taken with their lower density characteristics makes their use very interesting. 


\section{MATEC Web of Conferences}

Table 1. Number of European Standards by topics.

\begin{tabular}{|c|c|}
\hline Topics & Number \\
\hline Mechanical properties of CMC & 19 \\
\hline Thermal properties of CMC & 4 \\
\hline Fiber/matrix interface properties & 2 \\
\hline Methods of test for reinforcements & 10 \\
\hline Others & 4 \\
\hline
\end{tabular}

Table 2. Mechanical properties of CMCs- French, ISO, American and Japanese standard references.

\begin{tabular}{|c|c|c|c|c|}
\hline & & & & \\
\hline Mechanical properties of CMC & AFNORBA3C & 150 TC206 & ASTMC2807 & Ms \\
\hline Poom tencertuve - Tensile procenties & NFEN658-1 & 15015733 & (12725.95 & $15 R 1656$ \\
\hline Reom iencerture - Concressive propertes & NFEN658-2 & 15020504 & C1359-97 & 11581673 \\
\hline Room tencersine. Fexva propentes & NF ENGS8-3 & 15017138 & c1341 & 11581663 \\
\hline 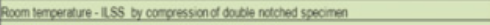 & NFEN6584 & 15020505 & (12.95-95 & . \\
\hline 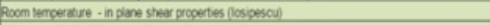 & NFEN 12289 & 15020506 & &. \\
\hline Proom temcerchure - Elastic propentes by ultusconc method & NFEN 14186 & NP18610 & C1198 & . \\
\hline 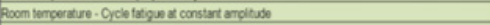 & NFEN 15156 & 15017140 & C1361.96 & 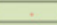 \\
\hline 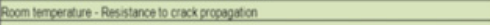 & NF EN 13234 & 15018608 & & . \\
\hline High iencerckive in if - Tensileprocentes & NF EN1893 & 15014574 & C1359-97 & 15 R1687 \\
\hline 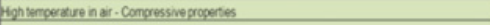 & NFEN12291 & 15014544 & $=$ & . \\
\hline Heghtencerave in ar - Fexua propentios & NFEN12789 & & - & . \\
\hline 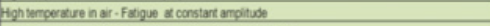 & NFEN15157 & 15017142 & 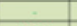 & ?. \\
\hline 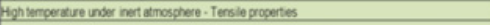 & NF EN 1892 & 15014574 & C1359 & . \\
\hline 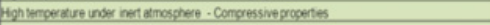 & NFEN 12290 & 15014544 & & 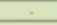 \\
\hline 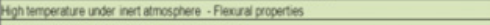 & NFEN12788 & 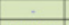 & (934) & - \\
\hline 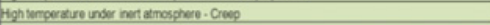 & NFEN13235 & TOP 1316 & 01337.96 & ?. \\
\hline 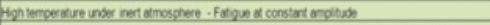 & NF EN15158 & - & 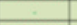 & . \\
\hline 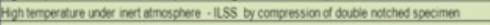 & NF EN1894 & - & C1425-99 &. \\
\hline Eightem & NFEN15335 &. & c1259 & . \\
\hline
\end{tabular}

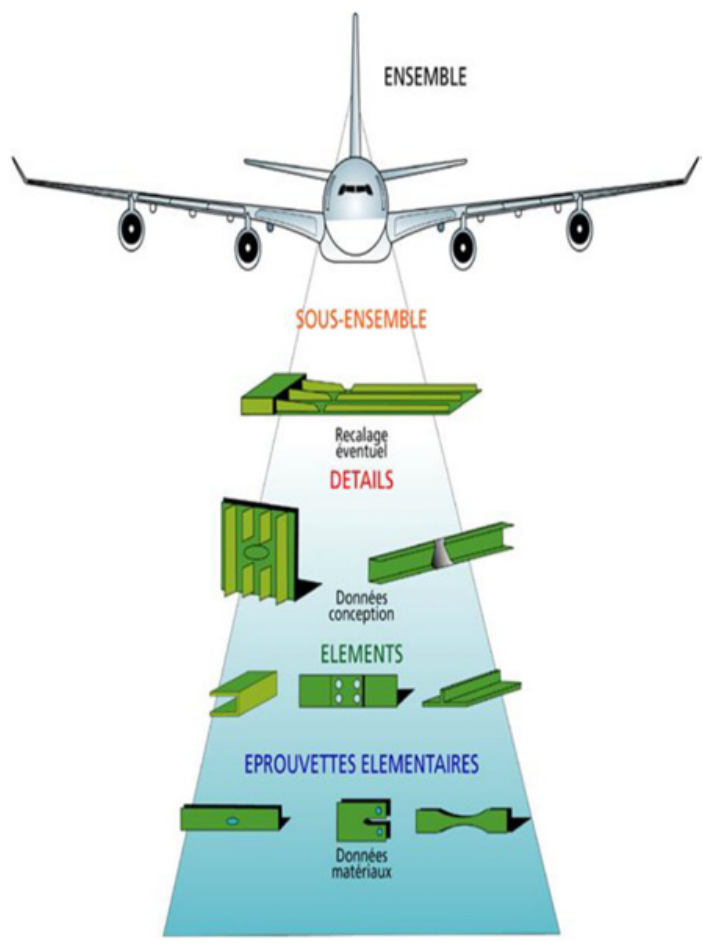

Figure 3. Pyramid of tests. 
The aeronautic and nuclear fields consider CMCs in industrial application projects where criticality is higher. The problem is now not only how to size components in terms of strength and life duration but also how to be sure that components have the probability of failure which respect the level of security required by the authorities.

For engine makers, the process to obtain the airworthiness certificate needs justifications that current standards cannot meet and specific requirements for nuclear applications are not covered by existing standards.

The aeronautics current standards cover the base of the pyramid of tests (see Fig. 3) composed of test methods to achieve elementary properties of CMCs. To meet the requirement of certification, the standardization should deal with details such as hole, assembly or corner, to provide minimum values for singularities. Furthermore the standardization could examine specific loadings in the case of entire components representative of the application's real life.

\section{Conclusion and perspectives}

Standards for the determination of elementary thermomechanical properties of CMCs have been obtained. The transfer of European standards to the ISO level has been undertaken in the framework of the ISOTC206 WG4 technical committee "Technical ceramics- ceramic matrix composites". This will be completed in a few years.

However CMC applications are approaching the industrialization phase, especially in aeronautics. This requires new standards to support and to complete the justification process for airworthiness qualification/certification.

These more product oriented standard will require cooperation at international level to share work (round robin campaign, task sharing, material coupons). This will be necessary to share costs, to reach a general agreement and above all to make the CMCs use reliable. 